\title{
Giant Galápagos tortoises; molecular genetic analyses identify a trans-island hybrid in a repatriation program of an endangered
} taxon

\author{
Michel C Milinkovitch*1, Daniel Monteyne1, Michael Russello², \\ James P Gibbs ${ }^{3}$, Howard L Snell ${ }^{4}$, Washington Tapia ${ }^{5}$, Cruz Marquez ${ }^{6}$, \\ Adalgisa Caccone ${ }^{2}$ and Jeffrey R Powell ${ }^{2}$
}

\begin{abstract}
Address: ${ }^{1}$ Laboratory of Evolutionary Genetics, Institute for Molecular Biology \& Medicine, Université Libre de Bruxelles, Rue Jeener \& Brachet 12 , 6041 Gosselies, Belgium, 2 Department of Ecology \& Evolutionary Biology, Yale Institute for Biospherics Studies ECOSAVE, Yale University, New Haven, CT 06520-8106, USA, ${ }^{3}$ College of Environmental Science and Forestry, State University of New York, Syracuse, NY 13210, USA, ${ }^{4}$ Department of Biology, University of New Mexico, Albuquerque, NM 87131, USA, ${ }^{5}$ Galápagos National Park Service, Puerto Ayora, Galápagos Islands, Ecuador and ${ }^{6}$ Charles Darwin Foundation, Puerto Ayora, Galápagos Islands, Ecuador

Email: Michel C Milinkovitch* - mcmilink@ulb.ac.be; Daniel Monteyne - dmonteyn@ulb.ac.be; Michael Russello - michael.russello@yale.edu; James P Gibbs - jpgibbs@syr.edu; Howard L Snell - snell@unm.edu; Washington Tapia - wtapia@spng.org.ec;

Cruz Marquez - marquez@fcdarwin.org.ec; Adalgisa Caccone - adalgisa.caccone@yale.edu; Jeffrey R Powell - jeffrey.powell@yale.edu

* Corresponding author
\end{abstract}

Published: 15 February 2007

BMC Ecology 2007, 7:2 doi:10.1186/1472-6785-7-2
Received: 29 September 2006

Accepted: 15 February 2007

This article is available from: http://www.biomedcentral.com/1472-6785/7/2

(C) 2007 Milinkovitch et al; licensee BioMed Central Ltd.

This is an Open Access article distributed under the terms of the Creative Commons Attribution License (http://creativecommons.org/licenses/by/2.0), which permits unrestricted use, distribution, and reproduction in any medium, provided the original work is properly cited.

\begin{abstract}
Background: Giant Galápagos tortoises on the island of Española have been the focus of an intensive captive breeding-repatriation programme for over 35 years that saved the taxon from extinction. However, analysis of 118 samples from released individuals indicated that the bias sex ratio and large variance in reproductive success among the 15 breeders has severely reduced the effective population size $\left(N_{e}\right)$.

Results: We report here that an analysis of an additional 473 captive-bred tortoises released back to the island reveals an individual (EI465) that exhibits nuclear microsatellite alleles not found in any of the 15 breeders. Statistical analyses incorporating genotypes of 304 field-sampled individuals from all populations on the major islands indicate that EI465 is most probably a hybrid between an Española female tortoise and a male from the island of Pinzón, likely present on Española due to human transport.

Conclusion: Removal of El465 as well as its father and possible (half-)siblings is warranted to prevent further contamination within this taxon of particular conservation significance. Despite this detected single contamination, it is highly noteworthy to emphasize the success of this repatriation program conducted over nearly 40 years and involving release of over 2000 captive-bred tortoises that now reproduce in situ. The incorporation of molecular genetic analysis of the program is providing guidance that will aid in monitoring the genetic integrity of this ambitious effort to restore a unique linage of a spectacular animal.
\end{abstract}




\section{Background}

Conservation genetics is a relatively new, yet growing field of research that can have immediate impact on practical issues confronting efforts to conserve biodiversity. Technical developments of molecular procedures directly applicable to genetic analysis of virtually any organism have made important contributions to these efforts. Here we present a unique example of the use of molecular conservation genetics to detect genetic contamination of an otherwise successful captive breeding-repatriation program of a once critically endangered species.

The genetically distinct population of giant Galápagos tortoises (Geochelone hoodensis, at times considered a subspecies of G. nigra) occupying the island of Española in the extreme southeastern region of the Galápagos archipelago was in grave danger of extinction in the late 1960s due to hunting activities from sealing, whaling, and pirate ships [1], as well as habitat destruction by feral goats. In response, the Charles Darwin Research Station (CDRS) and Galápagos National Park (PNG) initiated in late 1960 s a captive-breeding and reintroduction program [24]. By 1965, thorough searches across the island found only 14 remaining individuals (two males and 12 females) and all were transferred to the Breeding Centre on the island of Santa Cruz. In 1977, a third Española adult male from the San Diego Zoo (USA) was incorporated into the breeding program. The first tortoises whose parents originated from Española hatched at CDRS in 1971 and were subsequently released in 1975 after completion of a goat eradication campaign. To date, more than 2000 offspring have been repatriated, the island has undergone significant ecological recuperation, repatriated tortoises now reproduce in situ, and the core population of 15 parents continues to reproduce in captivity at the Breeding Centre.

As minimization of inbreeding is probably as important a determinant as rehabilitation of habitat for long-term survival of the repatriated population [5-8], we previously used molecular data to assess how much of the genetic diversity of the 15 breeders is represented in the repatriated population [9]. Analysis of 15 informative microsatellite loci allowed us to determine the captive parents of 118 surviving released individuals collected in 1994; at that time, this represented about $40 \%$ of the repatriated population. This analysis indicated that contributions of the 15 breeders are highly skewed. The large variance in reproductive success [10] in combination with a severely female-biased sex ratio [11] reduces the effective population size $\left(N_{e}\right)$ to an alarming low value of 5.7 [9]. Because the long-term $N_{e}$ is the harmonic mean across generations [11], we suggested rectifying the low $N_{e}$ in the parental population prior to continuation of the repatriation program. Indeed, estimating that $N_{e}$ for the current repatri- ated population is $1200, N_{e}$ over the two generations would only reach 11.3 . This is an overestimate as it is based on a $60 \%$ survival rate of released offspring (CDRS, personal communication), and on the optimistic assumption that sex ratio and reproductive success are not biased on the island. In other words, the current orchestration of the breeding program generated inbreeding that reduced genetic variation of the current population of about 1200 individuals to a level equivalent to that expected for, at best, a population of 11 unrelated individuals. Inbreeding could be effectively reduced by modification of the breeding program to more nearly equalize reproductive success among breeders.

In order to fine-tune the estimate of $N_{e}$ and analyse its evolution through time, we collected in 2003 and 2004 blood samples from 473 additional tortoises of which 316 were sampled on Española and 157 were samples of F1 individuals awaiting release. The latter point is of importance as it allows us to distinguish between differential reproductive success and differential survival rates [9].

\section{Results}

Surprisingly, one individual (E1465) sampled on Española (Fig. 1) exhibits one alien allele (i.e, not found in any of the 15 captive parents) at 8 of the 15 loci investigated (Table 1). It is therefore impossible that both parents of this individual are among the 15 breeders. Sequencing of a section of the control region in individual E1465 reveals the single haplotype identified previously [12] as specific to the Española population. These results suggest that E1465 is a hybrid between a female Española tortoise and a male from another island. To assess the geographic origin of the father, we genotyped E1465 at 9 loci (of which 4 overlap with the set of loci discussed above) that had been previously used for analysing genetic variability and population structure of giant tortoises across the whole archipelago [13]. The "alien" alleles revealed for E1465 are found at varying frequencies in populations throughout Isabela, Santiago, Pinzón, Santa Cruz, and San Cristóbal. Using a genotypic database of 304 fieldsampled individuals from all populations on the major islands, we performed assignment tests using Rannala and Mountain's approach [14] (as implemented [15] in GENECLASS2) and Pritchard et al.'s method [16] (as implemented [17] in STRUCTURE 2.1). The first method assigned E1465 with high probabilities to the Española and Pinzón island populations with log Likelihood values $(\log L)$ of -21.839 and -23.169, respectively. All other individuals sampled on Española exhibit much higher $\log \mathrm{L}$ values (ranging from -4.621 to -10.638; mean -6.965), assigning them to Española. The second approach also indicates that E1465 exhibits a mixed history, with large contributions from both Española and Pinzón (Fig. 2). 
0
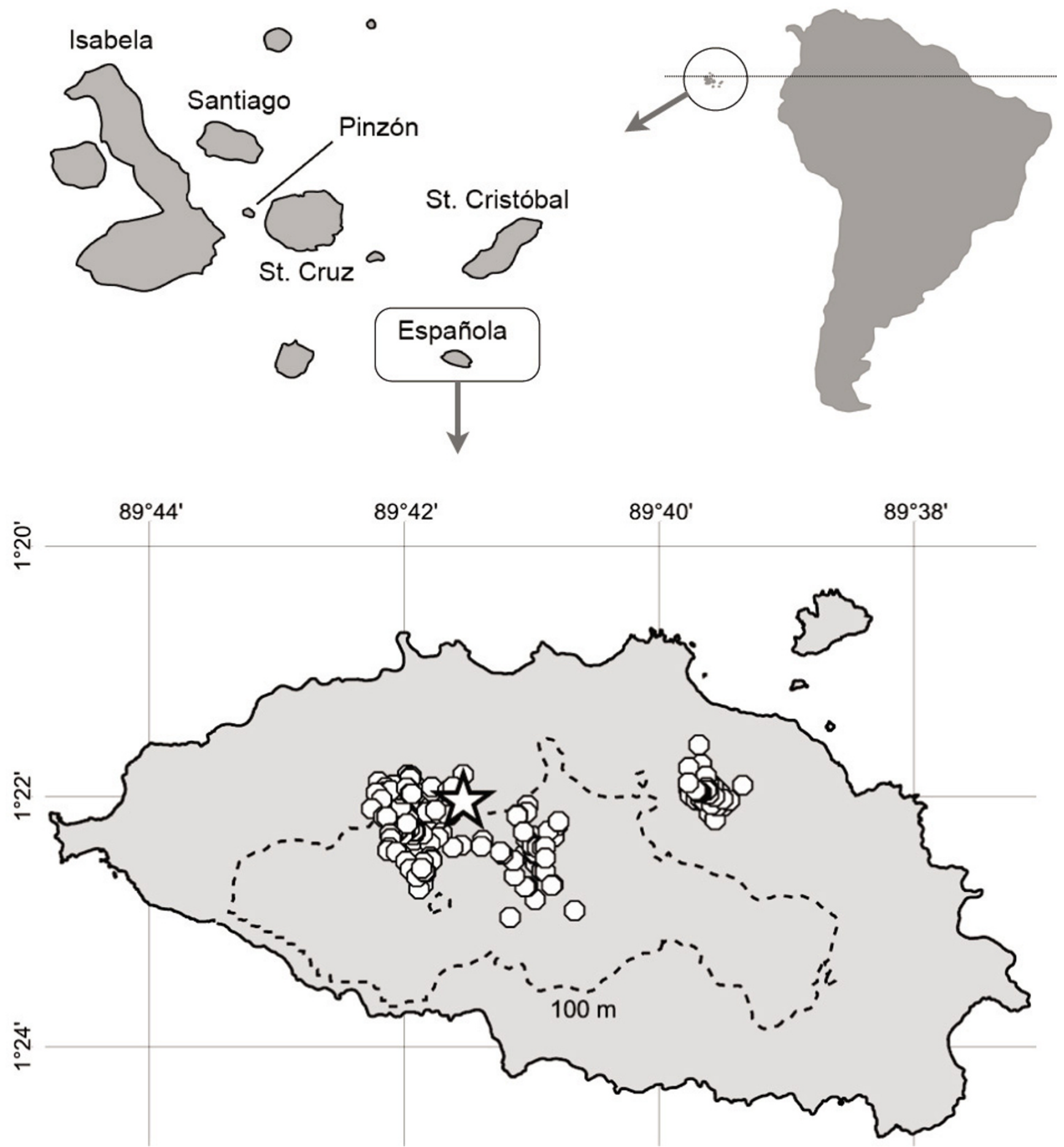

\section{Figure I}

Position of the 316 tortoises blood-sampled on Española in 2003. Circles represent individuals. The star corresponds to the position of individual EI465. The contour dotted-line indicates the 100 meter altitude level. The concentration of sampled individuals in two main areas reflects the localization of suitable habitat where the vast majority of tortoises congregate. 


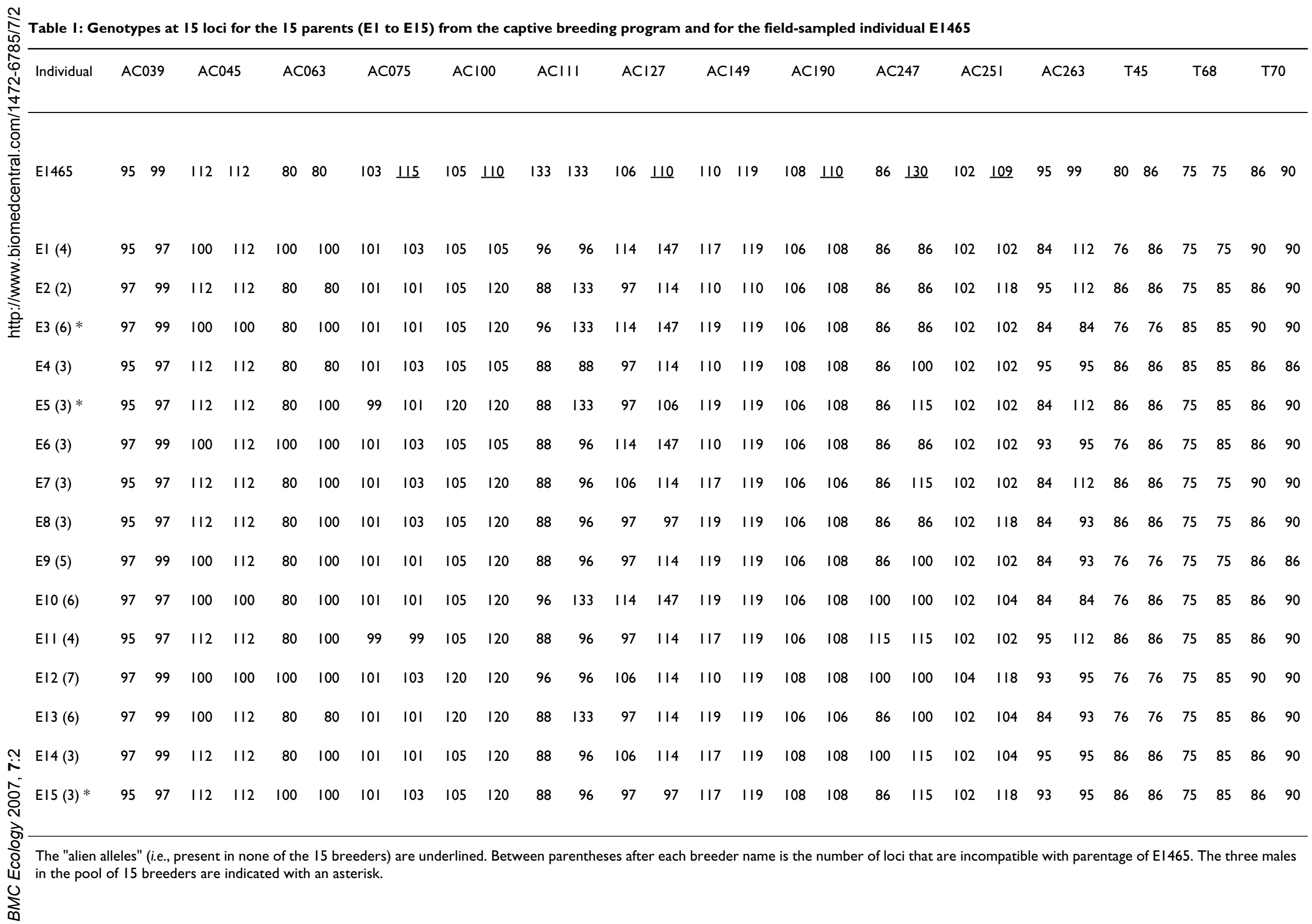



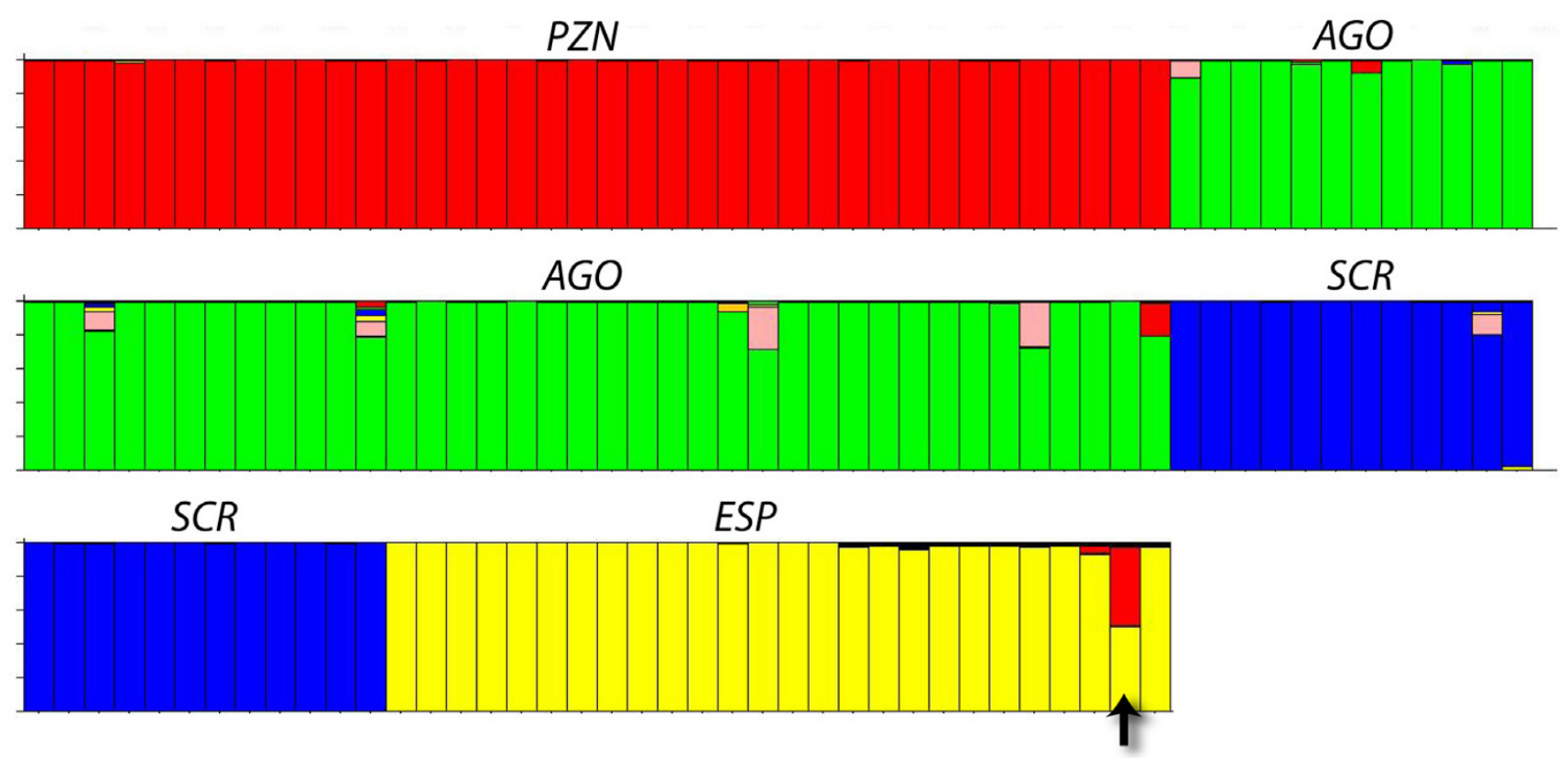

\section{Figure 2}

Inferred ancestry of individuals from the islands of Pinzón (PZN), Santiago (AGO), Santa Cruz (SCR), and Española (ESP) according to the Structure [17] analysis using prior population definitions. Membership coefficients are colour-coded according to islands: red (Pinzón), green (Santiago), blue (Santa Cruz), and yellow (Española). El465 (arrow) exhibits membership coefficients of $0.50 \mathrm{I}$ and $0.46 \mathrm{I}$ for Española and Pinzón, respectively (these values do not add up to one due to nominal associations with other clusters). Structure [17] analysis using a model of population admixture using all available genotypic data from all populations (not just 4) yielded very similar results (data not shown).

The most likely explanation is that E1465 is a hybrid between an Española female and a Pinzón male. Inspection of the genotype of E1465 (Table 1) indicates that none of the 12 captive females can be its mother (nor any of the three captive males can be its father), hence, the hybridization event must have taken place on Española (rather than at the captive breeding centre). The cause for the (past or current) presence of a Pinzón male on Española is unknown but is most likely linked to human transport. One possibility is the Pinzón male was a transplant due to the extensive exploitation and sometimes translocation of tortoises by 17-19th century whaling and other activities. It is conceivable that such an animal was missed in the attempts to find all remaining tortoises on Española in 1965. Such transplants have been detected on other islands (e.g., [12]). This would imply Pinzón genetic contamination should have been occurring for several generations, a possibility for which there is no evidence. Indeed, the fact that only a single such hybrid offspring has been found in a sample of 400+ survivors on Española (present data plus those in [9]) is strong evidence against long-term contamination. A more likely scenario is that early in the Española releases (early 1970s), a Pinzón male was accidentally incorporated into the repatriates. A captive breeding program of Pinzón tortoises at the cap- tive breeding centre predates the Española program, so Pinzón juvenile tortoises were present there at the time of release. Furthermore, it is noteworthy that morphologies of Pinzón and Española tortoises, especially as juveniles, are largely indistinguishable.

\section{Discussions and Conclusion}

Clearly, if one wishes to maintain the guideline/principle of restoring "natural" populations [18], it is important to remove from Española the individuals that compromise the integrity of the Española gene pool. In addition to E1465, we also need to search for the possible presence of its father and (half-) siblings. Note that we cannot rule out the possibility that the contaminating Pinzón individual may be a grand-parent of E1465. However, given that our estimate based on size is that E1465 is minimum 9 years old, and tortoises reach sexual maturity at about 20 years of age, it is impossible that E1465 is a grandchild of a male released within the last 35 years. Finding E1465 should be relatively easy because we marked it with a permanent Passive Integrated Transponder tag, as is the case for all individuals that we sampled on the island. Finding the father and its descendants will be more difficult, because they do not carry any tag, as their blood has never been sampled. We will therefore need to search for 
unmarked tortoises, sample them, and use a diagnostic field-based test that will allow us to differentiate Pinzón vsEspañola alleles. Note that, prior to 1991, all repatriated animals were marked at CDRS using shell notching. Unfortunately, this method is problematic for animals that have grown from about ca. $6 \mathrm{~cm}$ to $60-70 \mathrm{~cm}$ plastron length in a highly abrasive environment. Hence, we endorse the continued, systematic use of Passive Integrated Transponder tags for marking individuals upon release.

Regardless of the means by which Pinzon alleles have entered the Española lineage, our analysis (i) indicates that the rate of contamination of the Española breedingrepatriation program is very low, and (ii) underlines the utility of the approach used by the GNP and the CDRS, i.e., use molecular genetic approaches to monitor the breeding-repatriation program. One future step might be to routinely perform a diagnostic PCR-based test on all the tortoises that will be released in the future to assess their correspondence with the target population. Despite this detected single contamination, it is highly noteworthy to emphasize the success of this repatriation program conducted by the PNG and CDRS over nearly 40 years in difficult conditions and involving release of over 2000 captive-bred tortoises that now reproduce in situ. The recent incorporation of molecular genetic analysis of the program is providing further insights and guidance that will aid in assuring the survival of this unique linage of a spectacular animal.

\section{Methods}

Each sample was collected from the brachial vein of one of the front legs of the tortoise, preserved in a lysis buffer containing $0.1 \mathrm{M}$ of Tris-HCl, $0.1 \mathrm{M}$ of EDTA, $0.2 \mathrm{M}$ of $\mathrm{NaCl}$ and $1 \%$ sodium dodecyl sulphate (SDS) at a pH of 8.0 , and subsequently stored at $4^{\circ} \mathrm{C}$. About $200 \mu \mathrm{l}$ of each blood sample was digested at $37^{\circ} \mathrm{C}$ overnight in a buffer (100 mM Tris- $\mathrm{HCl}, 100 \mathrm{mM} \mathrm{NaCl}, 5 \mathrm{mM}$ EDTA, 0.5\% SDS) containing $200 \mu \mathrm{g}$ of proteinase K. Genomic DNA was isolated following standard phenol-chloroform extraction procedures [19]. DNA was resuspended in TrisEDTA (TE) buffer (10 mM Tris- $\mathrm{HCl}$ and $1 \mathrm{mM}$ EDTA at a $\mathrm{pH}$ of 7.2) and stored at $-20^{\circ} \mathrm{C}$. Microsatellite loci were from those characterized in [9] and in [13]. Genotyping was performed using PCR carried out in a total volume of $25 \mu \mathrm{l}$ containing $10-100 \mu \mathrm{g}$ of genomic DNA, $1 \times$ PCR buffer, $2 \mathrm{mM}$ of $\mathrm{MgCl} 2,0.25 \mathrm{mM}$ of each dNTP, $15 \mathrm{pm}$ of each primer (one with fluorescence labelling, the other with a GTTTCTT tail in 5' to force +A alleles) and 0.7 units of FastTaq DNA polymerase (Roche). Thermal profiles consisted of an initial denaturation step at $95^{\circ} \mathrm{C}$ for 4 min, followed by 35 cycles of $30 \mathrm{~s}$ at $95^{\circ} \mathrm{C}, 30 \mathrm{~s}$ at the annealing temperature and $30 \mathrm{~s}$ at $72^{\circ} \mathrm{C}$, with a final extension step of $60 \mathrm{~min}$ at $72^{\circ} \mathrm{C}$ (to force the formation of $+\mathrm{A}$ alleles). PCR products were separated by electrophoresis using an ABI 3730 capillary sequencer. Deterministic and probabilistic parentage analyses were performed with the program PAPA v2.0 [20].

Individuals of unknown ancestry were assigned to island populations based on their multi-locus genotypes using two separate approaches. First, the exclusion-simulation test of a partial Bayesian assignment method [14] was used to assign individuals to their population of origin as implemented in GENECLASS [15]. The exclusion threshold was set to 0.05 . In addition, a Bayesian model-based clustering method [16] for inferring population structure and assigning individuals to populations was employed as implemented in STRUCTURE 2.1 [17]. Membership coefficients $(q)$ of individuals were estimated following a Markov chain Monte Carlo simulation (MCMC) of $1 \times$ $10^{6}$ iterations following an initial burnin of $5 \times 10^{4}$ repetitions. Given the large body of research directed towards reconstructing population structure and genetic distinctiveness of the extant named taxa of G. nigra $[12,13,21,22]$, analyses were run using a model that utilized prior population information, as recommended by [16]. STRUCTURE analysis using a model of population admixture yielded very similar results (data not shown). The mitochondrial control region was sequenced as in [21].

\section{Authors' contributions}

MCM and DM generated the molecular data and performed the data analyses. MCM and JRP wrote the manuscript. MR participated to data analysis. MCM, JG, HLS, $\mathrm{WT}, \mathrm{CM}$, and AC localized and sampled all tortoise individuals used in the study. JRP conceived the study. All authors commented on the draft manuscript and approved the final manuscript.

\section{Acknowledgements}

We thank the Galápagos National Park and the Charles Darwin Research Station for scientific, logistical, and personnel support. Financial support was from the National Geographic Society, the Yale Institute for Biospherics Studies, the 'Communauté Français de Belgique' (ARC I I64/20022770), and the National Fund for Scientific Research Belgium (FNRS).

\section{References}

I. Townsend $\mathrm{CH}$ : The Galápagos tortoises in their relation to the whaling industry: a study of old logbooks. Zoologia 1925, 4:55-135.

2. Cayot L, Snell HL, Llerena W, Snell HM: Conservation biology of Galápagos reptiles: twenty-five years of successful research and management. In Captive management and conservation of amphibians and reptiles Edited by: Collins JT. New York: SSAR Publications; 1994:297-305.

3. Fritts TH, Snell HL, Cayot L, MacFarland C, Earsom S, Marquez C, Llerena W, Llerena F: Progress and priorities in research for the conservation of reptiles. Bull de I'Institut Royal des Sciences Naturelles de Belgique 2000, 70:39-45.

4. MacFarland C, Villa G], Toro B: The Galápagos giant tortoises (Geochelone elephantopus). II. Conservation methods. Biol Conserv 1974, 6:198-212. 
5. Coltman DW, Pilkington JG, Smith JA, Pemberton JM: Parasitemediated selection against inbred Soay sheep in a free-living island population. Evolution 1999, 53:1259-1267.

6. Lively CM, Craddock C, Vrijenhoek RC: Red Queen hypothesis supported by parasitism in sexual and clonal fish. Nature 1990, 344(6269):864.

7. Madsen T, Shine R, Olsson M, Wittzell H: Conservation biology: Restoration of an inbred adder population. Nature 1999, 402(6757): 34 .

8. Meagher S: Genetic diversity and Capillaria hepatica (Nematoda) prevalence in Michigan deer mouse populations. Evolution 1999, 53:1318-1324.

9. Milinkovitch MC, Monteyne D, Gibbs JP, Fritts TH, Tapia W, Snell HL, Tiedemann R, Caccone A, Powell JR: Genetic analysis of a successful repatriation programme: giant Galapagos tortoises. Proc Biol Sci 2004, 27 I (I 537):34I-345.

10. Lande R, Barrowclough GF: Effective population size, genetic variation, and their use in population management. In Viable populations for conservation Edited by: Soulé ME. Cambridge University Press; 1987:87-124.

1I. Wright S: Evolution in Mendelian populations. Genetics 193I, 16:97-159.

12. Caccone A, Gentile G, Gibbs JP, Frirts TH, Snell HL, Betts J, Powell JR: Phylogeography and history of giant Galapagos tortoises. Evolution Int J Org Evolution 2002, 56( I 0):2052-2066.

13. Ciofi C, Milinkovitch MC, Gibbs JP, Caccone A, Powell JR: Microsatellite analysis of genetic divergence among populations of giant Galapagos tortoises. Mol Ecol 2002, I I (I I):2265-2283.

14. Rannala B, Mountain JL: Detecting immigration by using multilocus genotypes. Proc Natl Acad Sci U S A 1997, 94(I 7):9197-920I.

15. Piry S, Alapetite A, Cornuet JM, Paetkau D, Baudouin L, Estoup A: GENECLASS2: a software for genetic assignment and firstgeneration migrant detection. J Hered 2004, 95(6):536-539.

16. Pritchard JK, Stephens M, Donnelly P: Inference of Population Structure Using Multilocus Genotype Data. Genetics 2000, 1 55:945-959.

17. Donnelly P, Falush D, Stephens M, Pritchard J, Wen W, Rosenberg N: STRUCTURE. 2. Ith edition. 2004.

18. Nicholls H: Tortoise conservation: one of a kind. Nature 2004, 429(699I):498-500.

19. Hillis D, Moritz C, Mable B: Molecular Systematics. Sunderland, MA: Sinauer; 1996.

20. Duchesne P, Godbout MH, Bernatchez L: PAPA (package for the analysis of parental allocation): a computer program for simulated and real parental allocation. Mol Ecol Notes 2002, 2:191-193.

21. Beheregaray LB, Ciofi C, Geist D, Gibbs JP, Caccone A, Powell JR: Genes Record a Prehistoric Volcano Eruption in the Galapagos. Science 2003, 302(5642):75.

22. Russello MA, Glaberman S, Gibbs JP, Marquez C, Powell JR, Caccone A: A cryptic taxon of Galapagos tortoise in conservation peril. Biology Letters 2005, I:287-290.
Publish with Bio Med Central and every scientist can read your work free of charge

"BioMed Central will be the most significant development for disseminating the results of biomedical research in our lifetime. "

Sir Paul Nurse, Cancer Research UK

Your research papers will be:

- available free of charge to the entire biomedical community

- peer reviewed and published immediately upon acceptance

- cited in PubMed and archived on PubMed Central

- yours - you keep the copyright
BioMedcentral 